\title{
Prediction and error growth in the daily forecast of precipitation from the NCEP CFSv2 over the subdivisions of Indian subcontinent
}

\author{
Dhruva Kumar Pandey ${ }^{1}$, Shailendra Rai ${ }^{1,2, *}$, A K Sahai ${ }^{3}$, S Abhilash ${ }^{3}$ and N K Shahi ${ }^{1}$ \\ ${ }^{1}$ K. Banerjee Centre of Atmospheric and Ocean Studies, University of Allahabad, Allahabad 211 002, India. \\ ${ }^{2}$ M.N. Saha Centre of Space Studies, University of Allahabad, Allahabad 211 022, India. \\ ${ }^{3}$ Indian Institute of Tropical Meteorology, Dr. Homi Bhabha Road, Pashan, Pune 411 008, India. \\ ${ }^{*}$ Corresponding author.e-mail: raishailry@gmail.com
}

This study investigates the forecast skill and predictability of various indices of south Asian monsoon as well as the subdivisions of the Indian subcontinent during JJAS season for the time domain of 20012013 using NCEP CFSv2 output. It has been observed that the daily mean climatology of precipitation over the land points of India is underestimated in the model forecast as compared to observation. The monthly model bias of precipitation shows the dry bias over the land points of India and also over the Bay of Bengal, whereas the Himalayan and Arabian Sea regions show the wet bias. We have divided the Indian landmass into five subdivisions namely central India, southern India, Western Ghat, northeast and southern Bay of Bengal regions based on the spatial variation of observed mean precipitation in JJAS season. The underestimation over the land points of India during mature phase was originated from the central India, southern Bay of Bengal, southern India and Western Ghat regions. The error growth in June forecast is slower as compared to July forecast in all the regions. The predictability error also grows slowly in June forecast as compared to July forecast in most of the regions. The doubling time of predictability error was estimated to be in the range of 3-5 days for all the regions. Southern India and Western Ghats are more predictable in the July forecast as compared to June forecast, whereas IMR, northeast, central India and southern Bay of Bengal regions have the opposite nature.

\section{Introduction}

The south Asian monsoon brings most of the rainfall over southeast Asia during June-July-AugustSeptember (JJAS) season. The understanding of the peculiarity in the monsoon and its accurate prediction is still a challenge for the scientific community involved in the process. The economy of India largely depends on agriculture which is dependent on monsoon. India receives $80 \%$ of its annual rainfall during JJAS season (Kumar et al. 2010). Hence, the timely and accurate prediction is not only important to scientific community but it is directly related to the society. The India Meteorological Department (IMD) is engaged in giving long-range forecast of seasonal mean rainfall over India for more than 100 years with varying degrees of success (Rajeevan 2001). Improvement in the prediction skill is not satisfactory even after eight decades of statistical forecast of IMD (Gadgil et al. 2005; DelSole and Shukla 2012).

The atmospheric general circulation models (AGCMs) have been used to simulate and predict the south Asian summer monsoon (Kang and Shukla 2006) but its performance over monsoon region is not appropriate (Gadgil and Sajani 1998;

Keywords. Indian monsoon; CFS; predictability; forecast error; NCEP; Lorenz curve. 
Kang et al. 2002, 2004; Wang et al. 2004; Kumar et al. 2005). It has been established that the coupled general circulation models (CGCMs) which include ocean-atmosphere interactions are better in simulating the south Asian summer monsoon (Kumar et al. 2005; Wang et al. 2005). The major modelling centers of the world use the coupled models for their national seasonal forecasting system. India has also started to provide extended and long-range dynamical prediction of monsoon with the help of coupled models on experimental basis.

In the present study, we have used Climate Forecast System version 2 (CFSv2) of National Centre of Environmental Prediction (NCEP). The CFSv2 is a fully-coupled general circulation model used in seasonal forecasting and has shown better forecast skill over United States for surface temperature and precipitation and also simulate the El Nino-Southern Oscillation (ENSO) variability accurately (Saha et al. 2010). In the present version, all the aspects of forecast system including model components, data assimilation system and ensemble configuration are changed (Saha et al. 2010). Recently, CFSv2 has been extensively used by India for operational long range prediction (Abhilash et al. 2014b) and a reliable prediction is obtained (Sharmila et al. 2013).

The CFSv2 was used by Indian Institute of Tropical Meteorology (IITM), Pune, India for operational extended range monsoon forecasting under 'National Monsoon Mission' (NMM) (Saha et al. 2014a; Abhilash et al. 2014b). Extensive works related to the improvement in the monsoon prediction on intraseasonal, interannual and decadal time scale were done in the last 2 years (Pattanaik and Kumar 2013; Sahai et al. 2013; Sharmila et al. 2013; Goswami et al. 2014; Pattanaik and Kumar 2014). However, the mean monsoon rainfall over India shows large spatial variations, with the west coast and northeast India receiving heavy rainfall, while central and south peninsula receives less rainfall (Rajeevan et al. 2000). Guhathakurta et al. (2014) have analyzed the trend and epochal variability of Indian summer monsoon over the country as a whole and four homogenous regions and it is found that, different regions of India have experienced significant changes in the frequency of days in rainfall with different intensities. Kashid and Maity (2012) have shown by genetic algorithm (GA) that the prediction of Indian summer monsoon rainfall over India is better than different homogenous regions. The accurate and timely prediction at regional level is also important, keeping in mind the needs of the population living in these regions in terms of agriculture, power, etc. Although, the forecast over small regions of the Indian subcontinent is important, it is difficult to implement the same using statistical techniques
(Rajeevan et al. 2004). The main focus of this study is related to summer monsoon rainfall over the entire India as a whole and the subdivisional level of Indian subcontinent.

The extensive studies have been done for the atmospheric predictability in the past and it is established that the instantaneous state of the atmosphere cannot be predicted beyond few weeks (Lorenz 1965, 1969; Smagorinsky 1969; Shukla 1985). There are many techniques for the estimation of predictability such as signal-to-noise ratio (Mohan and Goswami 2003; George and Sutton 2006; Kug et al. 2010) and analysis of variance (Shukla 1981), etc., of the forecasting model. Almost all the studies discussed above have used the forecast on monthly and seasonal time scale for the predictability analysis.

The forecast error arises due to uncertainty in the initial condition and model imperfection. However, the uncertainty in the initial condition is responsible only for predictability error. It was proposed by Lorenz $(1982,1985)$ that the predictability error provides the upper bound of predictability, whereas forecast error provides lower bound. This method is widely used to estimate the forecast skill and predictability of various climate models (Shukla 1985; Savijarvi 1994; Shukla and Kirtman 1996; Bengtsson and Hodges 2006; Rai and Krishnamurthy 2011). Drbohlav and Krishnamurthy (2010) have assessed the forecast skill and predictability of the CFS version 1 in predicting the seasonal mean monsoon rainfall on monthly and seasonal means, whereas Rai and Krishnamurthy (2011) have done this on daily means, but these studies are in terms of precipitation on the entire Indian land mass. It has been reported previously that error growth rates are different for different spatial scales (Straus and Paolino 2009). The doubling time of small errors in the mid-latitudes is about $2-2.5$ days (Lorenz 1982; Simmons and Hollingsworth 2002).

It is also important to understand forecast error growth on daily time scale in different regions of the Indian subcontinent. The extent to which forecasts are reliable on daily time scales for different regions of the Indian subcontinent is useful from the point of view of the socio-economic impact perspective. The rate of error growth in different regions of India and the time taken to reach the limit of predictability will be estimated in the present work. This study will estimate the doubling time of small errors for different parts of India in CFSv2. In this study, we will follow the methods used by Lorenz (1982) because we want to discuss the growth of forecast and predictability error on the daily forecasts and this method has been proved to be most suitable for this kind of study. This method was previously used to analyze daily forecast and 
predictability error from CFS version 1 and the way to compute error doubling time on daily time scale is given in Rai and Krishnamurthy (2011) and readers are advised to refer this and the references therein for further details. The main goal of the present study is to investigate the forecast skill and predictability of south Asian monsoon in CFSv2 on daily time scale for the whole Indian region as well as different regions of the Indian subcontinent.

The model, data and method used in this paper are described in section 2. The daily climatological monsoon mean rainfall and the monthly model bias of precipitation will be presented in section 3 . The description about forecast and predictability error analysis of precipitation will be discussed in sections 4 and 5, respectively. The summary and conclusions are described in section 6 .

\section{Model and data settings}

CFSv2 is a fully coupled land-atmosphere-ocean model which was developed by NCEP (Saha et al. 2010). The atmospheric component of CFSv2 is NCEP global forecast system (GFS) at T126 resolution $(\sim 100 \mathrm{~km})$ with 64 vertical levels. The ocean component is Modular Ocean Model version 4p0d (Griffies et al. 2004) of Geophysical Fluid Dynamics Laboratory (GFDL) at $1.0^{\circ} \times 1.0^{\circ}$ grid spacing with 40 vertical layers having 27 layers in the upper $400 \mathrm{~m}$ with maximum depth of approximately 4.5 $\mathrm{km}$. The atmosphere and ocean models are coupled with no flux adjustment.

The atmospheric and ocean initial conditions (ICs) for model integrations have been obtained from the coupled atmosphere-ocean-sea-ice-land reanalysis from NCEP, known as climate forecast system reanalysis (CFSR) (Saha et al. 2010). The main aim of creating these already spunned up atmospheric and ocean ICs was to run the CFSv2 model in the hindcast or retrospective forecasts mode to generate seasonal and 45 days of subseasonal time series of model forecasts for the purpose of generating climatology from each model integration dates for calibration to be used for operational real-time sub-seasonal and seasonal predictions. In this work, we have adopted the same strategy as NCEP implemented for real-time seasonal and sub-seasonal predictions, with an exception that we slightly perturb the atmospheric ICs obtained from CFSR to generate ensembles of ICs, in addition to one unperturbed/control one (Abhilash et al. 2014a).

CFSv2-coupled model runs with the initial conditions on 31 May, 30 June, 30 July, 29 August and 28 September each year having 11 ensemble members and each run gives forecast for 45 days (Abhilash et al. 2014b). The errors were removed in the dynamical extended range prediction using an approach similar to the 'complex-and-same-model environment group' (Buizza et al. 2008) and generate ensembles of different initial conditions. The slight perturbation in the initial conditions of the atmospheric model with a random number at each grid point is used and different ensemble members were generated. It is advised that the readers to refer Abhilash et al. (2014a) and Sahai et al. (2013) for details on perturbation techniques used in the model. However, keeping in mind the huge computational power requirement to run large ensemble members in real-time basis, an ensemble of 10 perturbed atmospheric initial conditions has been developed in addition to one actual initial condition.

We will denote the forecast initialized on 31 May, 30 June, 30 July, 29 August and 28 September as June, July, August, September and October forecast respectively, hereafter. In the present study, we have taken the first 30 days data from each forecast of 45 days from all the five initial conditions and in this way we get daily continuous rainfall data from 1 June to 12 November for 13 years during 2001-2013. We have also used the 45-day forecast with different initial conditions for the estimation of forecast error and predictability error by the model. The observed precipitation data during 2001-2013 on the daily time scale has been taken from Global Precipitation Climatology Project, One Degree Daily Precipitation Observed Rainfall Data Set (GPCP) version 1.2 on $1^{\circ} \times 1^{\circ}$ resolution for verification (Huffman et al. 2001). The observed daily rainfall data have been taken from IMD for the verification over the land points of India (Pai et al. 2014).

\section{Results and discussion}

\subsection{Mean and bias}

The CFS version 1 forecasts of precipitation and winds on daily time scale has been analyzed and discussed by Rai and Krishnamurthy (2011) and Krishnamurthy and Rai (2011). In this section, the performance of the CFSv2 model with respect to observation in terms of daily climatology and bias of precipitation will be discussed.

\subsubsection{Seasonal cycle}

The daily climatology of the precipitation is calculated as the mean over the period 2001-2013 for each calendar day. We have computed two monsoon indices (IMR and EIMR) which will be described in the later section of the paper and the daily climatological mean for these indices are shown in 
(a) IMR

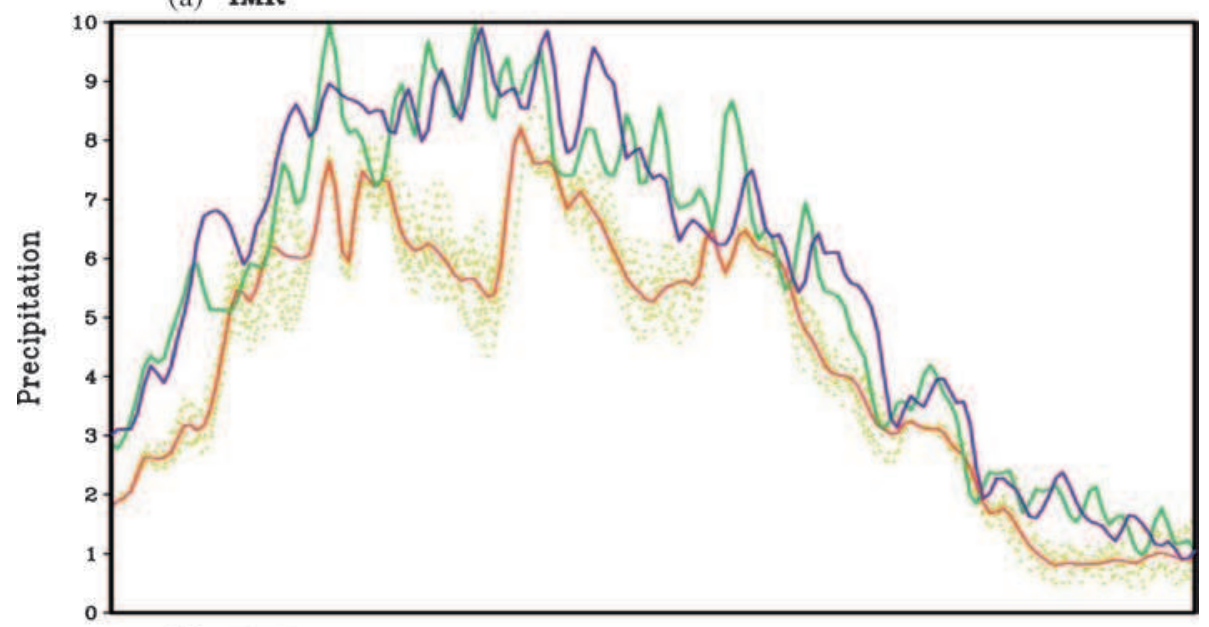

(b) EIMR

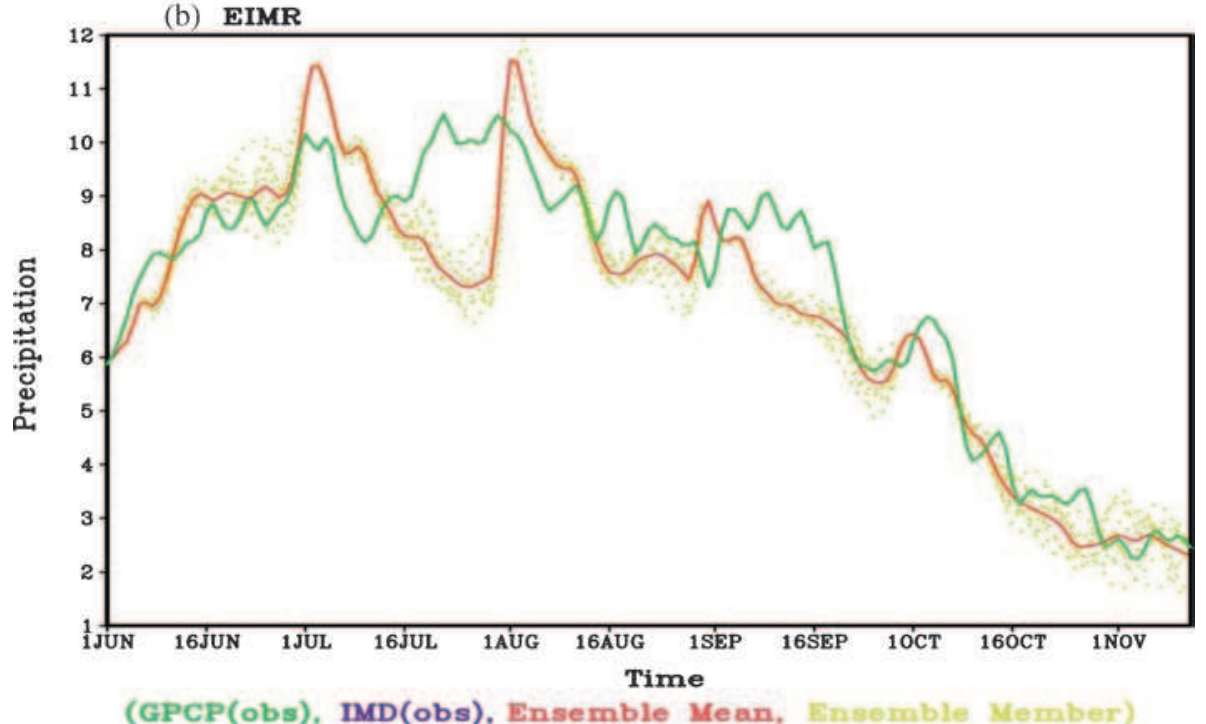

Figure 1. Seasonal cycle of daily climatological means of (a) IMR and (b) EIMR indices for observation (green), ensemble mean (red) and ensemble member of forecasts (yellow). In (a), the IMR index using the IMD observed rainfall is also shown by violet colour line. The period for computing the climatology is 2001-2013. Units are in $\mathrm{mm} \mathrm{d}^{-1}$.

figure 1. The seasonal cycles of all the 11 ensemble members, ensemble mean with respect to the observation during 1 June-12 November are shown in figure 1.

The Indian monsoon rainfall (IMR) index is computed as the area average of precipitation over the land points of India and is plotted in figure 1(a) with respect to GPCP and IMD observation. The model shows underestimation of precipitation up to $2-5 \mathrm{~mm} /$ day during developing and mature phase of the monsoon from 1 June to 1 August with respect to GPCP as well as IMD observation. However, the model is in agreement with observation during the retreat phase of the monsoon. The underestimation of precipitation over land points of India with respect to observation has already been reported in the previous studies from CFSv2 (Sahai et al. 2013; Sharmila et al. 2013; Abhilash et al. 2014b; Goswami et al. 2014; Bombardi et al.
2015) as well as CFSv1 (Rai and Krishnamurthy 2011; Abhilash et al. 2014a).

The extended Indian monsoon rainfall index (EIMR) includes the oceanic region of the Arabian Sea and Bay of Bengal and is defined as the area average of precipitation over the spatial domain $70^{\circ}-110^{\circ} \mathrm{E} ; 10^{\circ}-30^{\circ} \mathrm{N}$ (Goswami et al. 1999). The model produced EIMR shows good resemblances with GPCP observation with underestimation of 2-3 mm/day from 15 July to 1 August. This indicates that the model forecast of precipitation is overestimated over the ocean and it compensates the underestimated forecast of precipitation over the land region.

It is also important to study the extent to which the forecasts are reliable on daily time scales for different regions of Indian subcontinent from the point of view of the socio-economic needs of a particular region. We have computed JJAS 


\section{Climatology of JJAS for GPCP observation}
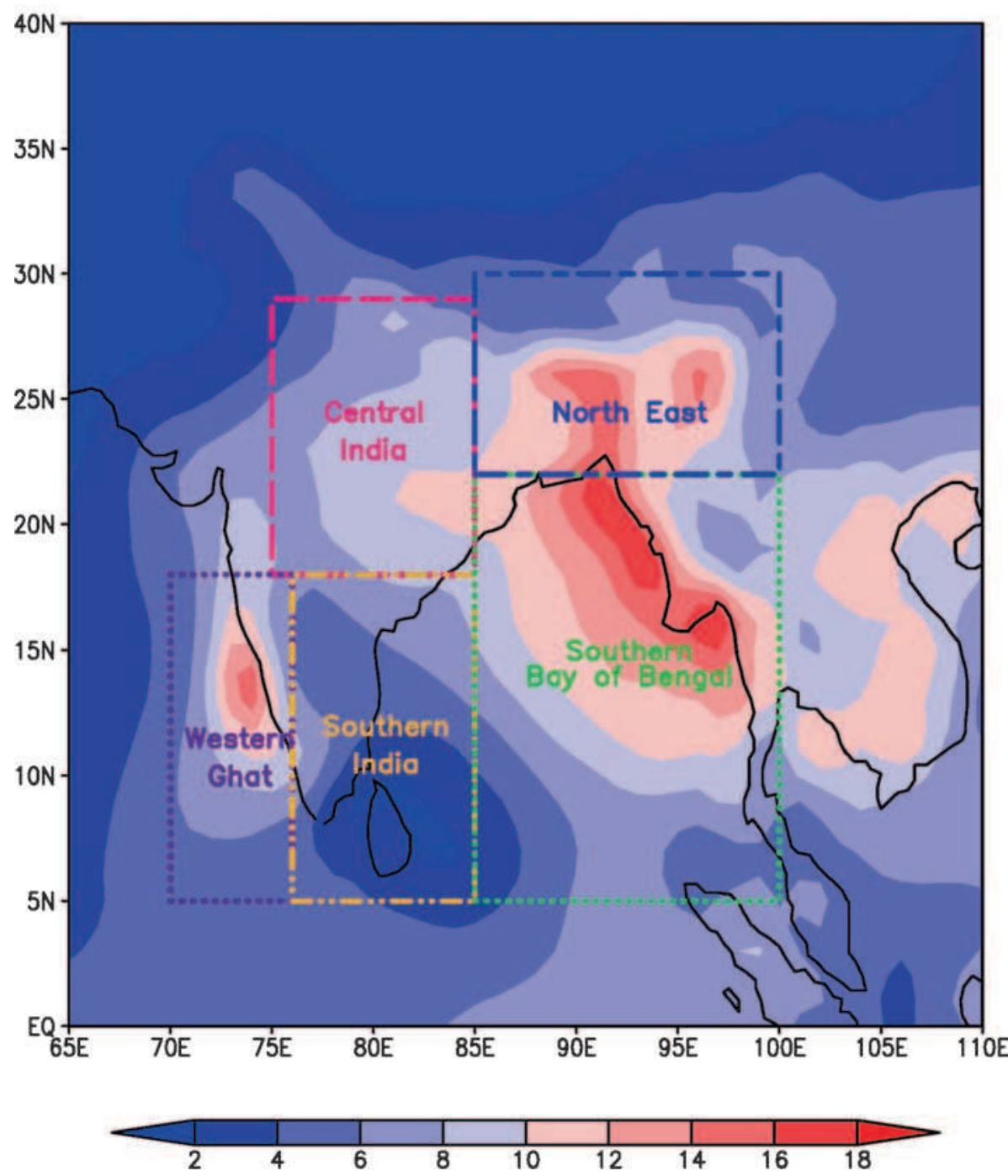

Figure 2. The precipitation climatology for JJAS season from GPCP observation. The five subdivisions of our interest are shown in boxes and named as central India $\left(75^{\circ}-85^{\circ} \mathrm{E} ; 18^{\circ}-30^{\circ} \mathrm{N}\right)$, northeast $\left(85^{\circ}-100^{\circ} \mathrm{E} ; 18^{\circ}-30^{\circ} \mathrm{N}\right)$, southern India $\left(76^{\circ}-85^{\circ} \mathrm{E} ; 5^{\circ}-18^{\circ} \mathrm{N}\right)$, southern Bay of Bengal $\left(85^{\circ}-100^{\circ} \mathrm{E} ; 5^{\circ}-25^{\circ} \mathrm{N}\right)$ and Western Ghats $\left(70^{\circ}-76^{\circ} \mathrm{E} ; 5^{\circ}-18^{\circ} \mathrm{N}\right)$.

precipitation from GPCP observation and shown in figure 2. This shows large spatial variations of precipitation over India with west coast and northeast India receiving heavy rainfall, while central and south peninsula receiving less mean monsoon rainfall. We have divided the entire domain in five regions namely central India $\left(75^{\circ}-85^{\circ} \mathrm{E} ; 18^{\circ}-\right.$ $\left.30^{\circ} \mathrm{N}\right)$, northeast $\left(85^{\circ}-100^{\circ} \mathrm{E} ; 22^{\circ}-30^{\circ} \mathrm{N}\right)$, southern India $\left(76^{\circ}-85^{\circ} \mathrm{E} ; 5^{\circ}-18^{\circ} \mathrm{N}\right)$, southern Bay of Bengal $\left(85^{\circ}-100^{\circ} \mathrm{E} ; 5^{\circ}-22^{\circ} \mathrm{N}\right)$, Western Ghat $\left(70^{\circ}-76^{\circ} \mathrm{E}\right.$; $\left.5^{\circ}-18^{\circ} \mathrm{N}\right)$ and are shown in figure 2 with the help of rectangular boxes.

The daily climatological mean of precipitation of the above regions is calculated over the land points and are shown in figure 3. The pattern of daily mean precipitation for central India is close to IMR with the underestimation of precipitation from 1 June to 1 September (figure 3a). The model shows good resemblance with the observation for other regions except an underestimation from 15 July to 1 August for southern Bay of Bengal, southern India and Western Ghat regions (figure $3 \mathrm{~b}-\mathrm{e})$. This indicates that the underestimation of precipitation during mature phase of monsoon for IMR region comes mostly from central India, southern Bay of Bengal, southern India and Western Ghat region, whereas the underestimation during the developing phase comes from central India and southern Bay of Bengal. We also compared these indices by including ocean region and the pattern was found similar to figure 3 with an overestimation for Western Ghat region throughout the monsoon season (figure not shown). 


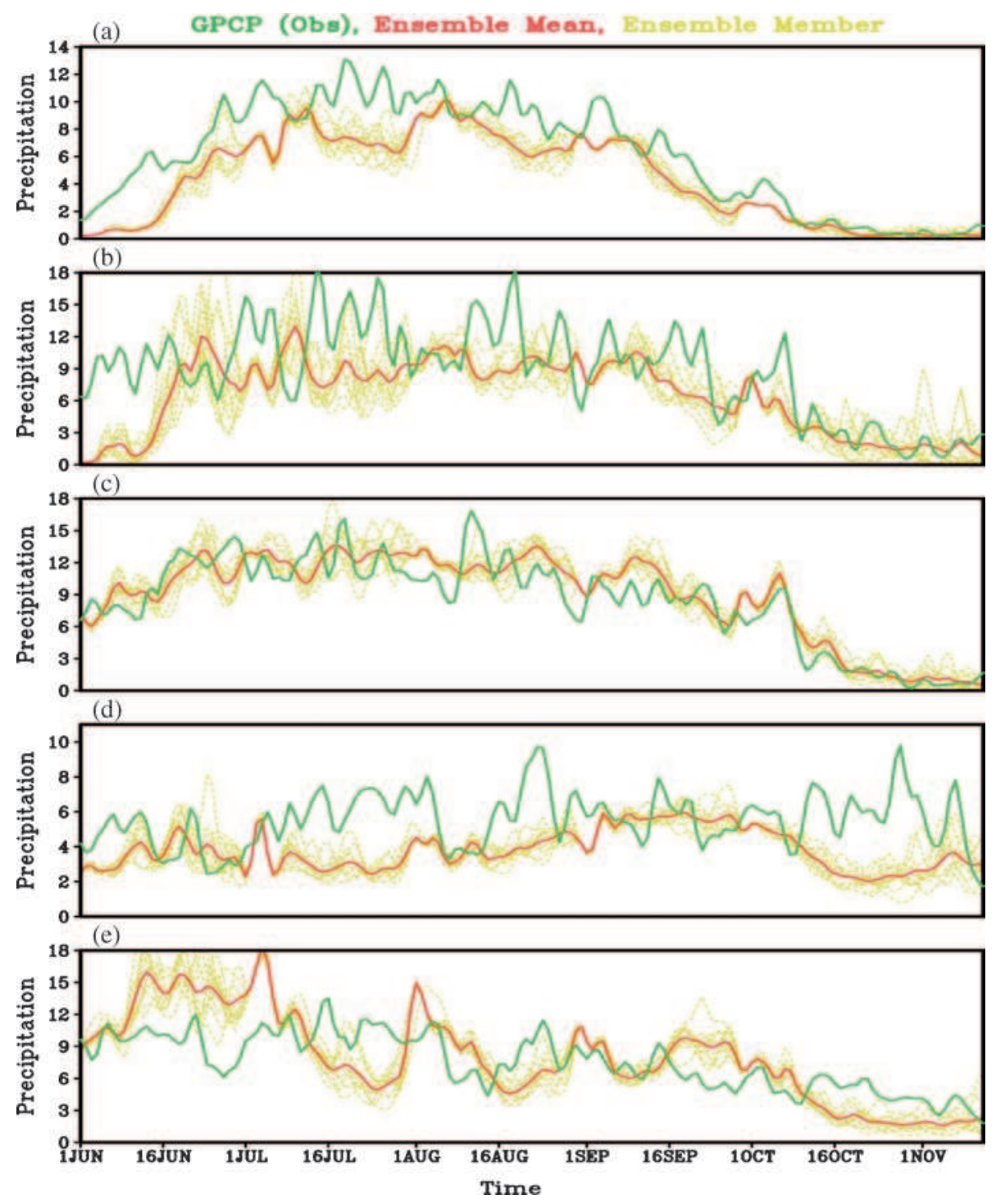

Figure 3. Seasonal cycle of daily climatological means over land area of (a) central India, (b) southern Bay of Bengal, (c) northeast, (d) southern India, and (e) Western Ghats. The period for computing the climatology is 2001-2013. Units are in $\mathrm{mm} \mathrm{d}^{-1}$.

\subsubsection{Model bias}

The model behaves differently for the months of June, July, August and September; so we have computed monthly biases of model with respect to GPCP observation for these months as shown in figure 4. The model shows underestimation over the land points of India and Bay of Bengal region. It has been observed that the centre of maxima for the dry bias is varying from month to month. However, overestimation for eastern Uttar Pradesh and Bihar was seen during July-September (figure $4 \mathrm{~b}-\mathrm{d}$ ). The model shows wet bias over the Himalayan region and Arabian Sea along with the coast of Western Ghats consistently during the monsoon season and this has been pointed out in some of the previous studies also (Saha et al.
$2013,2014 b)$. We also computed these biases over land points of the Indian subcontinent with respect to IMD observation and found similar patterns (figure not shown). The dry bias over land points of India in CFSv1 (Pattanaik and Kumar 2014) still persists in the CFSv2.

\section{Forecast error}

The difference between the predicted and the observed values are known as forecast error. The forecast error is generated due to the model imperfection and uncertainty in the initial condition. In this study, forecast skill of CFSv2 is evaluated by temporal correlation and error growth for various monsoon indices defined above. 

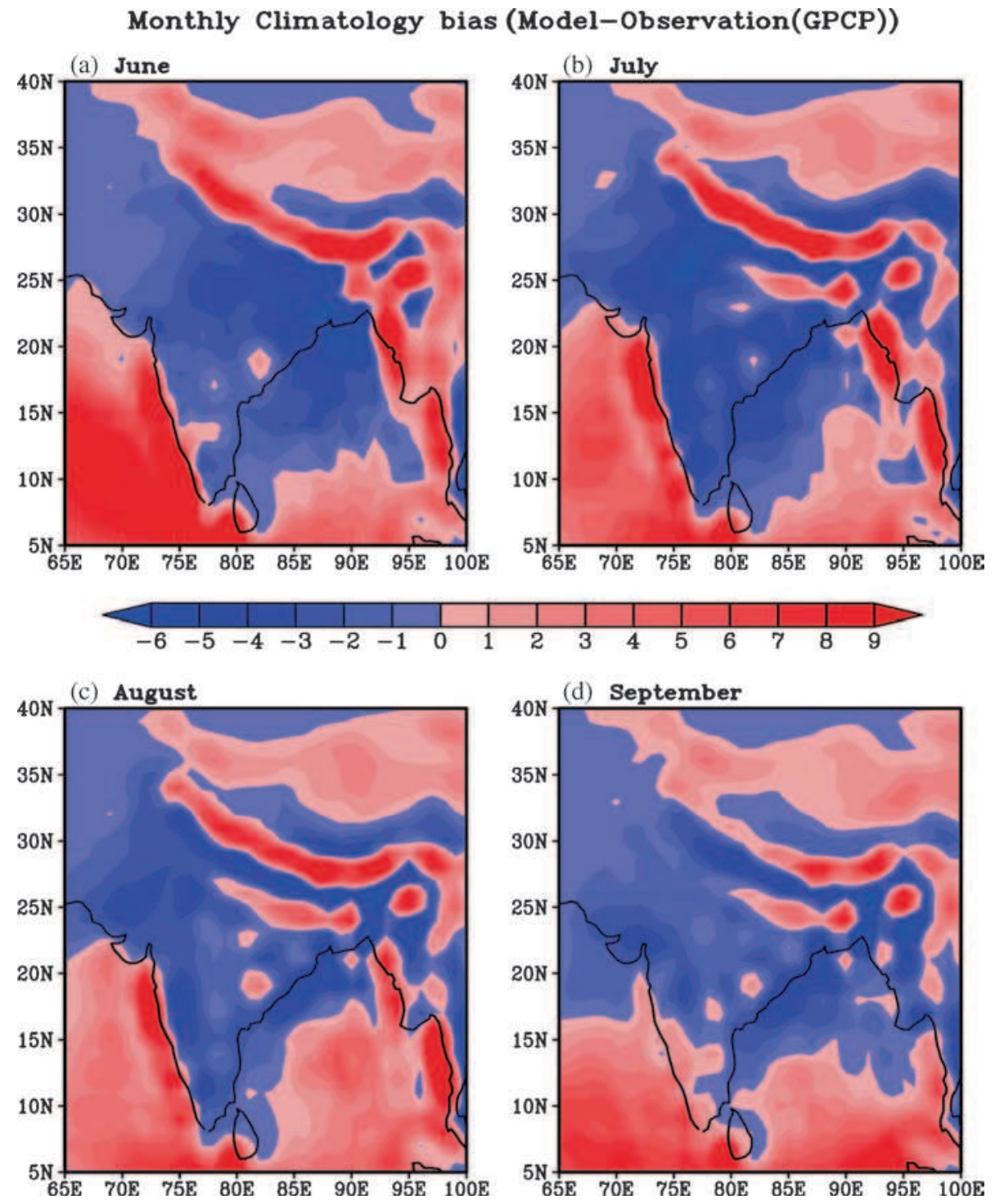

Figure 4. Monthly bias for (a) June, (b) July, (c) August, and (d) September with respect to GPCP observation.

\subsection{Temporal correlation}

The temporal correlation of different monsoon indices is used for the study of interannual variability of forecast skill of the model. It is computed for the period of Indian summer monsoon season (JJAS) of each year between the daily time series of forecast and observation for different monsoon indices such as IMR and EIMR. The correlation above 0.19 is significant above $95 \%$ confidence level for the daily precipitation data of 122 days during JJAS season using Student's 2-tail $t$-test. The temporal correlation of each ensemble member and ensemble mean of precipitation for IMR and EIMR indices are shown in figure 5. Temporal correlation lies between -0.3 and 0.5 for these two monsoon indices (figure 5). The low or negative value of correlation shows that the forecast and observation are not in phase and model is unable to forecast the intraseasonal oscillation properly. The IMR index shows more interannual variability as compared to the EIMR index and the value of temporal correlation of ensemble mean in this region is $>0.19$ for 5 years out of 13 years, which is statistically significant at $95 \%$ confidence level. It is observed that the correlations for EIMR region are better as compared to IMR index because the correlation values are found to be positive above the significant level of $95 \%$ after the year 2003. The temporal correlation for different subdivision of Indian subcontinent is also computed and they are not consistent and significant during the time domain of 2001-2013 (figure not shown).

\subsection{Forecast error growth}

We have computed forecast error by taking the difference between the predicted and the observed values on each calendar day of each year. Further, we have calculated root mean square error 

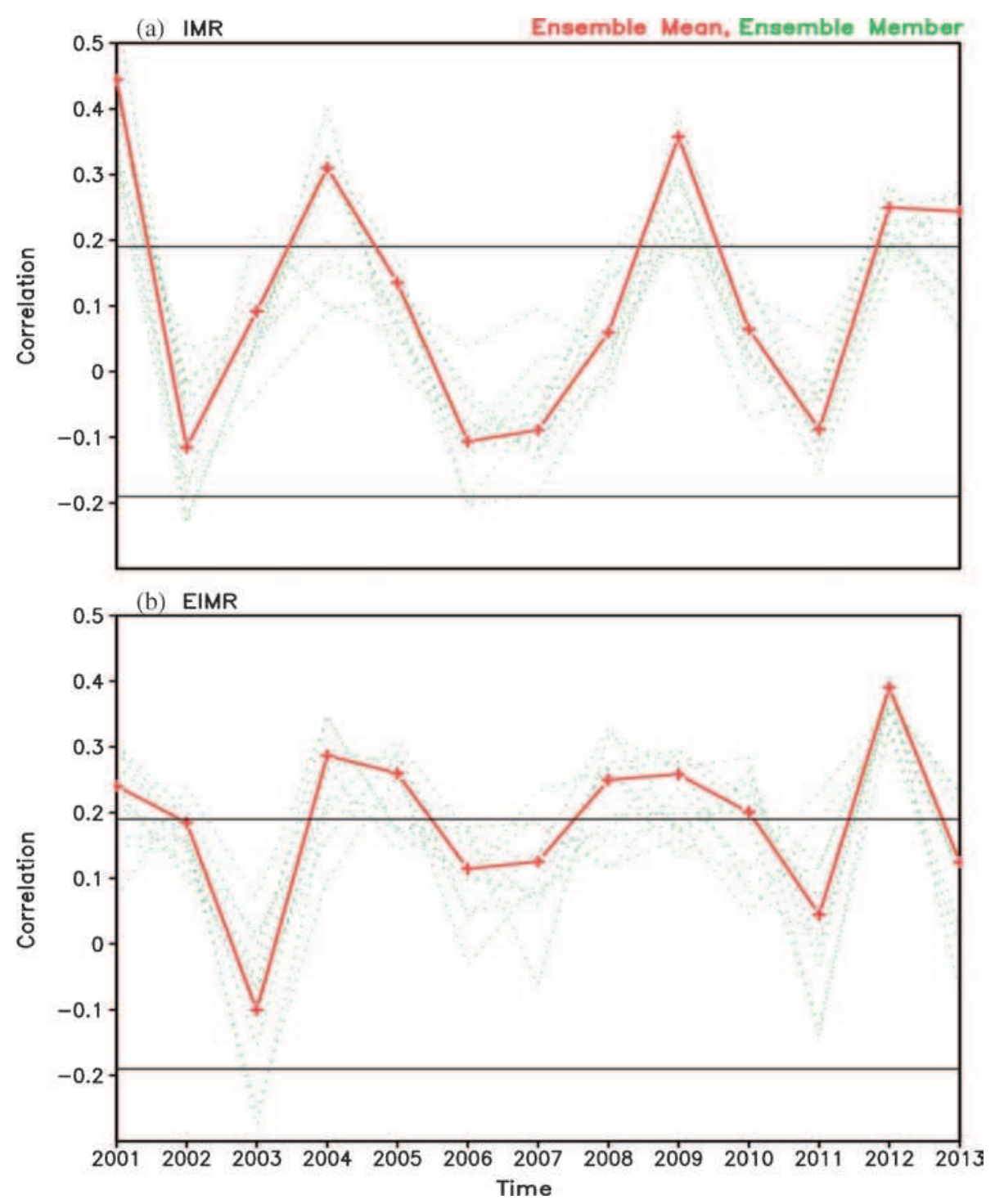

Figure 5. Temporal correlation between forecast and observation for JJAS season: (a) IMR and (b) EIMR.

(RMSE) during 2001-2013 for each ensemble member and the ensemble mean is taken. The evolution of daily error growth is computed for IMR and EIMR regions and is shown for June and July forecasts.

The RMSE of IMR index with respect to GPCP observation is shown in figure 6(a) and it is found that the error grows slowly for June forecast and saturates around 7 July. The error growth in July forecast is faster as compared to June and it reaches at saturation around 5 July. We have observed that the rate of growth in forecast error for IMR region for June forecast is slower as compared to July (figure 6a). Moreover, the initial value of error for July forecast is large but their growth rate is faster, so error reached the saturation value earlier as compared to June forecast. If the error becomes maximum and it fluctuates or decreases after this value, then we can say that the error reached at its saturation. The forecast error growth with respect to IMD observation has been computed and shown by dotted line in figure $6(\mathrm{a})$. The pattern is similar from IMD observation as it was from GPCP. It was observed that the initial value of forecast error for all the initial conditions with respect to IMD observation is less as compared to GPCP observation. The error growth rate for the forecast initialized on 31 May is slow and it may be due to the fact that the monsoon is in initial phase and has not reached most parts of the Indian subcontinent. We have also computed the error doubling time in the case of forecast error for IMR using the method described in section 5.2 in this paper. It is found that the doubling time error in case of IMR is 4.4 days and 3.5 days for June and July forecasts, respectively. It is clear from that 

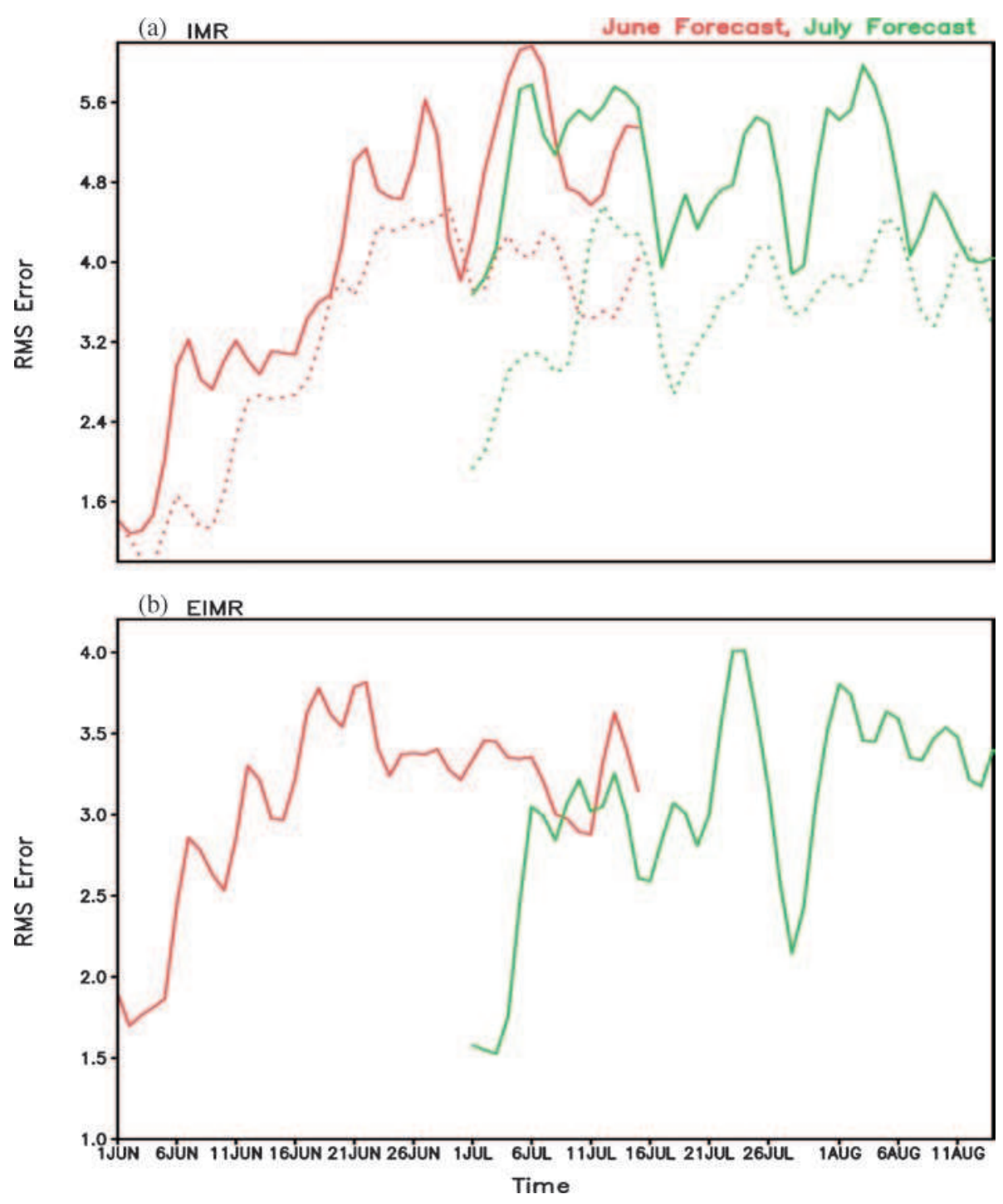

Figure 6. RMSE of forecast error with respect to GPCP observation for (a) IMR and (b) EIMR index for June (red) and July forecast (green). In (a), the IMR index using the IMD observed rainfall is also shown by dotted lines. Units are in $\mathrm{mm} \mathrm{d}^{-1}$

the error growth is slower in June forecast and it is more predictable as compared to July forecast for IMR.

It is observed that the initial value of RMSE for July forecast is lower for EIMR as compared to IMR. It may be due to the fact that EIMR region includes some parts of Indian Ocean and the model shows excess rainfall over ocean which compensates the less rainfall over the land points of India. However, the error growth rate is faster and reaches saturation early for the June and July forecast of EIMR index as compared to IMR (figure $6 \mathrm{~b}$ ). It may be due to the fact that EIMR includes the Bay of Bengal and Arabian Sea where the monsoon rainfall started before the onset of monsoon season and the model forecast is overestimated over these regions. The error growth rate of July forecast is fastest as compared to June forecast for EIMR.
The similar results were also observed in the case of CFSv1 (Krishnamurthy and Shukla 2011; Rai and Krishnamurthy 2011).

We have also computed the error growth curves over the land points for the five subdivisions defined above for June and July forecast and are shown in figure 7 . The rate of error growth is higher for July forecast as compared to June forecast for all the subdivisions (figure 7). These computations are also done by including the ocean part and a similar behaviour is found (figure not shown). We have discussed the forecast error only for June and July forecast because other forecasts showed large fluctuations in the error growth curves and it was difficult to guess the time of saturation.

CFSv2 is a coupled model and it is very difficult to point towards any particular component for large RMSE value of precipitation over the land 
(a) Root Mean Square Error of June forecast

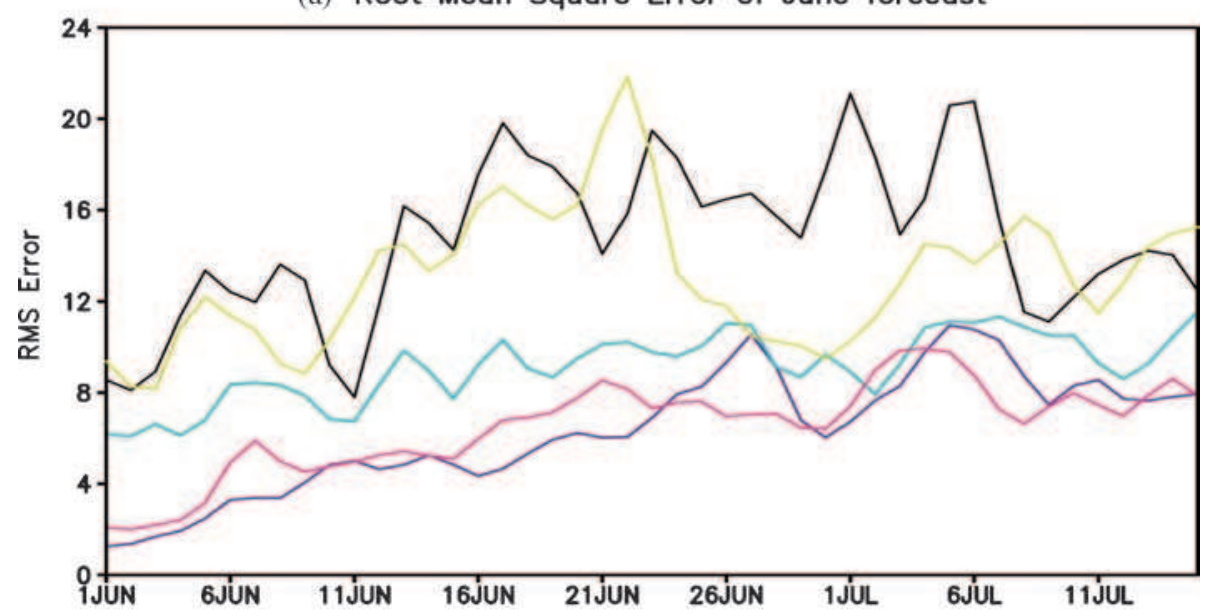

(b) Root Mean Square Error of July forecast

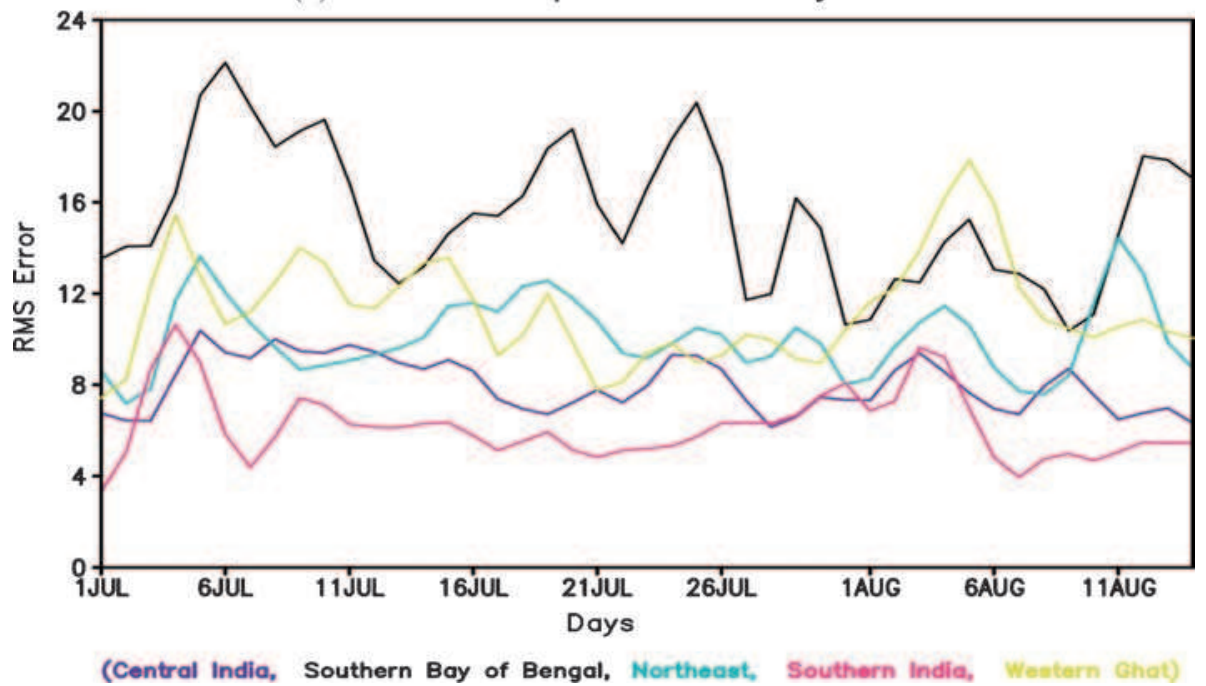

Figure 7. RMSE of forecast error with respect to GPCP observation of central India, southern Bay of Bengal region, northeast, southern India, and Western Ghats for (a) June and (b) July forecast. Units are in $\mathrm{mm} \mathrm{d}^{-1}$.

point of India. There may be multiple factors for error in prediction over landmasses, such as SST bias over the Indian Ocean, cloud parameterization schemes used in the model, land-atmosphere temperature contrast in pre-monsoon season, land surface feedback, etc. These factors may contribute to dry bias and large RMSE over the land points of India and extensive study is required to quantify the reasons responsible for it.

\section{Predictability of model}

We have computed predictability error of model by taking one ensemble member as truth and computed the difference of precipitation from rest of the ensemble members with this member. The error in the forecast is due to the uncertainty in the initial conditions and this error gives the upper bound of predictability of the model (Lorenz 1982).

\subsection{Growth of predictability errors}

The method to calculate predictability error is similar to the forecast error, but we have taken ensemble member 1 as truth in place of the observation. We have described the predictability error for June and July forecast only because error growth curves for other months were showing large fluctuations. Hence it was difficult to guess the time of saturation in computing doubling time of errors for other forecasts. The rate of predictability error growth for IMR region is steeper for July forecast as compared to June forecast (figure 8a). It has been observed that the predictability error for IMR reaches the saturation level after 25 days and 12 days respectively, in case of June and July forecast (figure 8a). However, predictability errors for EIMR grow slowly as compared to IMR and the time taken to reach the saturation value is similar for June and July forecast (figure 8b). This is in 

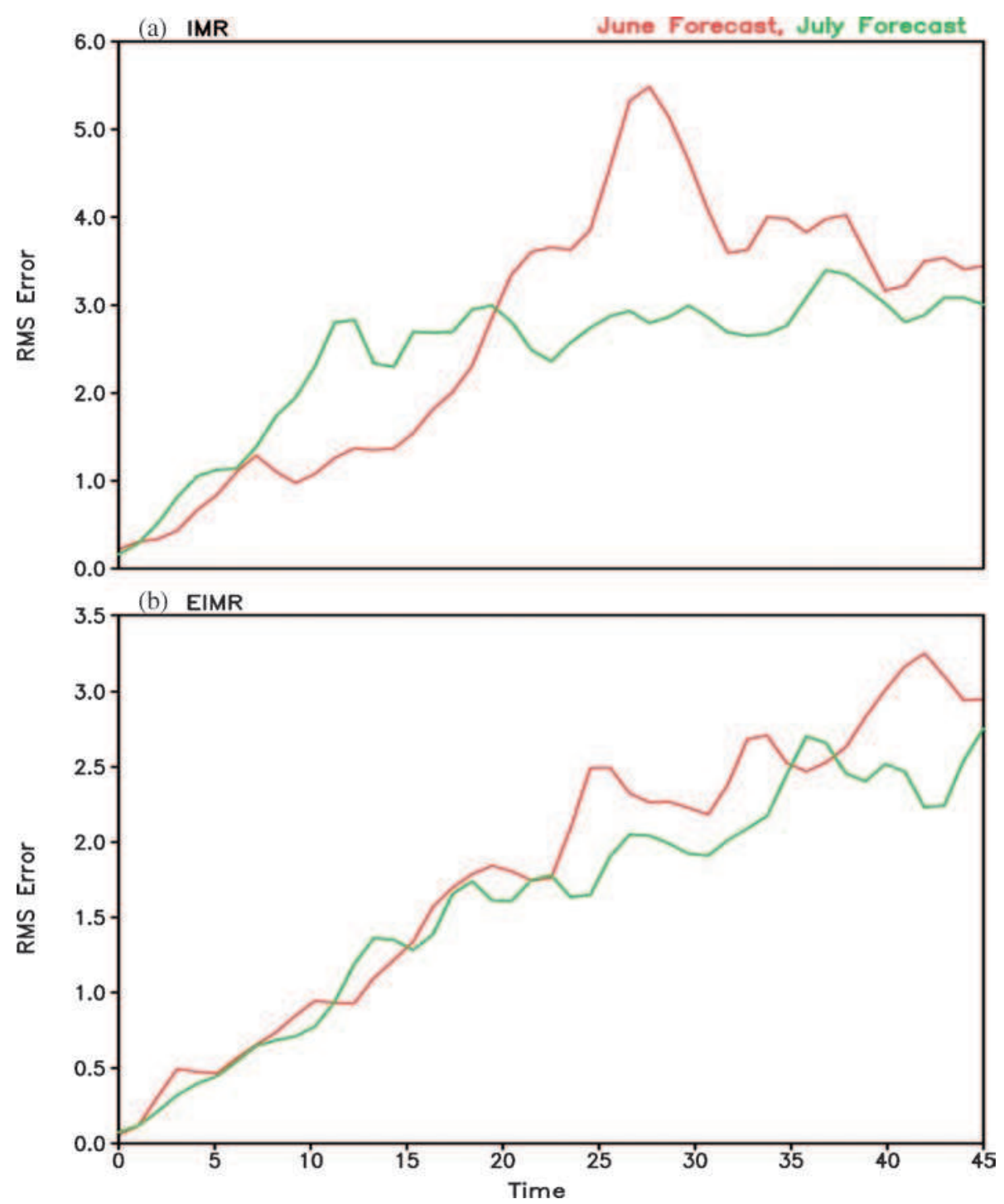

Figure 8. RMSE of predictability errors for (a) IMR and (b) EIMR indices for June and July forecast. Units are in $\mathrm{mm} \mathrm{d}^{-1}$.

conformity with the previous studies from CFSv1 (Abhilash et al. 2013) and CFSv2 (Pattanaik and Kumar 2013). However, the predictability of CFSv1 for IMR is reliable for the period of $1-2$ weeks but in case of CFSv2, it extends up to 3 weeks (Pattanaik and Kumar 2013).

We have also computed the predictability error over the land points of five subdivisions defined above for June and July forecast and shown in figure 9 . The predictability error of all five subdivisions, reach saturation level after 23 days and 10 days respectively, in case of June and July forecast (figures 9 and 10). The forecast of CFSv2 for the different subdivisions of Indian subcontinent may be reliable for more than two weeks, whereas it was only for less than one week for CFSv1 (Pattanaik and Kumar 2013). It is observed that the error growth for southern and central India for June forecast is slower as compared to other regions (figure 9a). The error grows slowly in case of June forecast as compared to July forecast for central India, northeast and southern Bay of Bengal as observed for IMR region. However, no change in the rate of predictability error is observed from June and July forecast for southern India region. The Western Ghat behaves differently and the rate of predictability error in July is smaller than June forecast. We also did the above computation by including the ocean in the five subdivisions as shown in figure 10 . The improvement in the predictability was observed when the ocean part is also included in all the five regions. The behaviour of error growth curve show similar nature from June and July forecast for all the regions except central India and northeast which is obvious because a tiny portion of this region lies in the ocean (figure 10a, b). The quantitative estimates of the predictability errors of these regions discussed will be estimated in the later section of this paper. 
(a) Predictability Error of June forecast

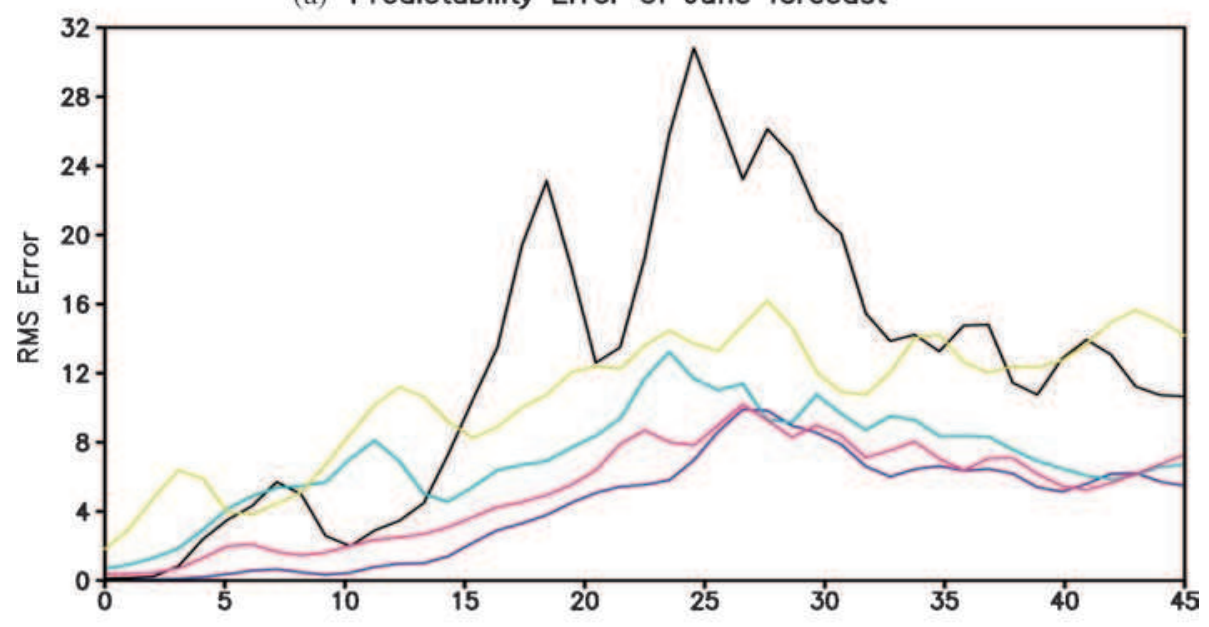

(b) Predictability Error of July forecast

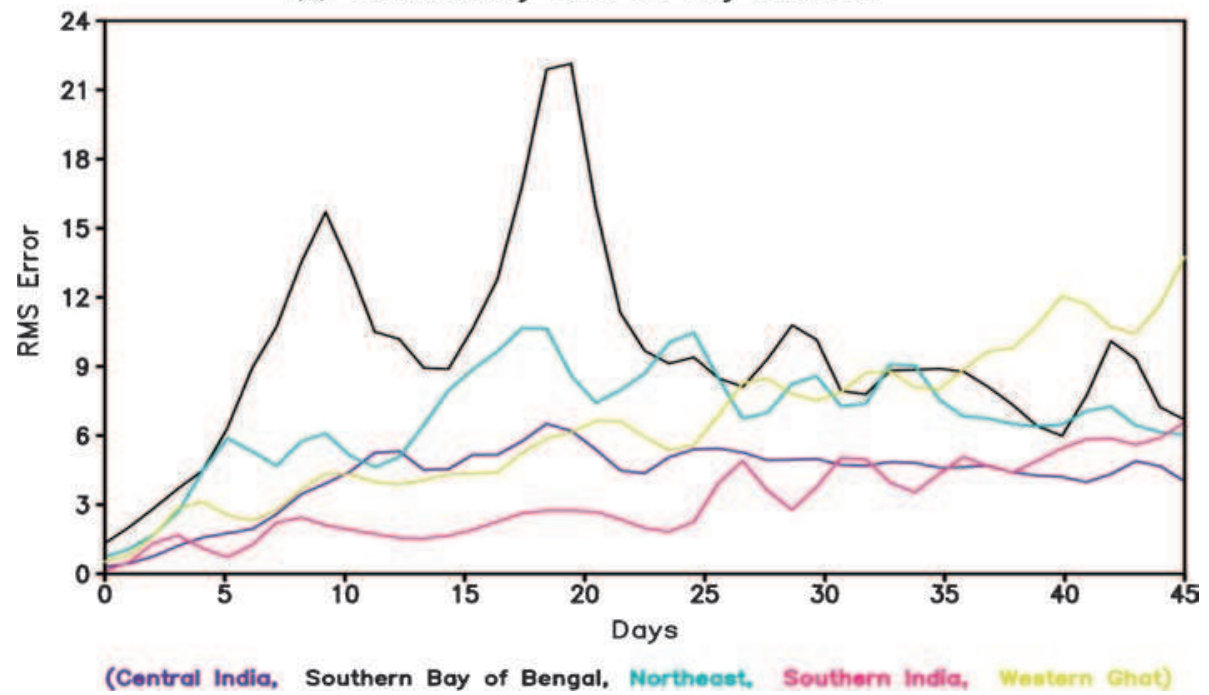

Figure 9. RMSE of predictability error with respect to GPCP observation of central India, southern Bay of Bengal region, northeast, southern India and Western Ghats for (a) June and (b) July forecast. Units are in $\mathrm{mm} \mathrm{d}^{-1}$.

\subsection{Quantitative estimation of growth rate}

The method to estimate the forecast and predictability error quantitatively in a nonlinear dynamical system using the empirical formula by Lorenz (1982) is applied for the climate models in many of the previous studies (Krishnamurthy and Shukla 2011; Rai and Krishnamurthy 2011). This formula has been found to be useful in estimating the error growth rate of small error. The Lorenz error equation for the nonlinear part of error growth having magnitude $E$ is represented as:

$$
\frac{\mathrm{d} E}{\mathrm{~d} t}=\lambda E-s E^{2},
$$

where $\lambda$ is the growth rate of the error and it is also known as the first Lyapunov exponent of the system (Krishnamurthy 1993) and $s$ is the saturation value which satisfies the condition $E_{s}=\lambda / s$.
If the magnitude of error at an initial time $t_{0}$ is $E_{0}$, then the solution of equation (1) is given by

$$
E=\frac{1}{2} E_{s}\left[1+\tanh \left\{\frac{1}{2} \lambda\left(t=t_{0}\right)-\tanh ^{-1}\left(1-2 \frac{E_{0}}{E_{s}}\right)\right\}\right],
$$

$t_{d}=\ln 2 / \lambda$, where $t_{d}$ is the doubling time error of small error.

We have estimated the value of growth rate $(\lambda)$ of predictability error (shown in figures 8,9 and $10)$ by fitting the error with equation (2). The best fit of error curves to equation (2) was obtained by the method described in Rai and Krishnamurthy (2011) and references therein. The daily predictability error curves of figures 8, 9 and 10 are used to calculate the value of $\lambda$. The daily predictability error curve over land region of central India (figure 9a) has been plotted along the best fit curve obtained from Lorenz's empirical 
(a) Predictability Error of June forecast

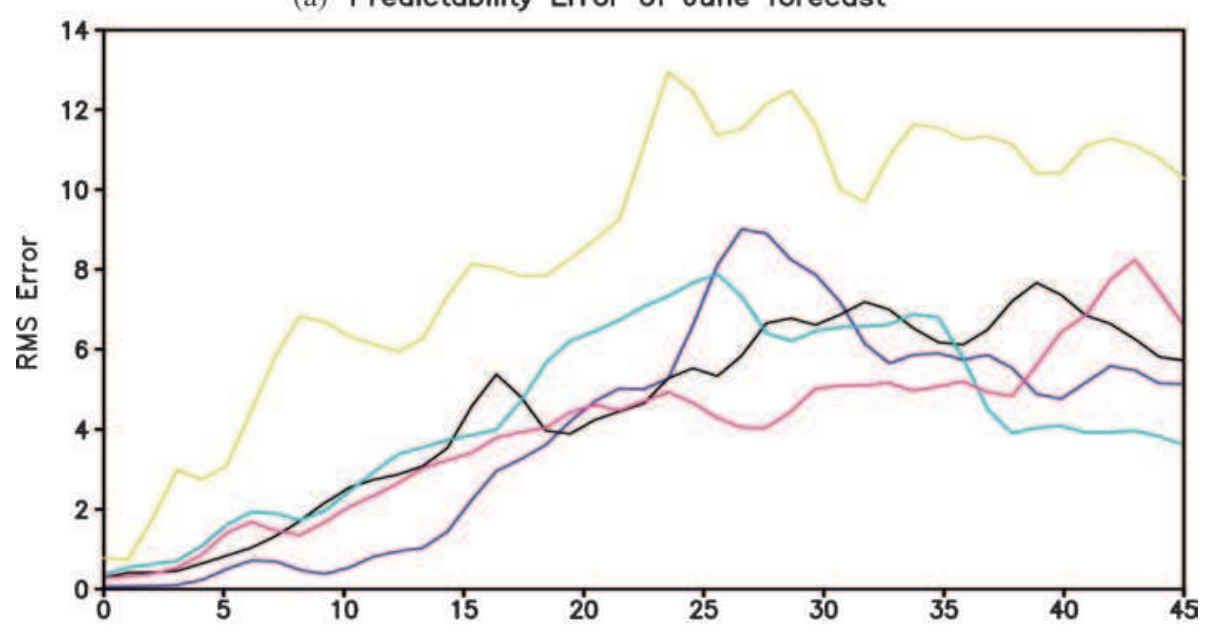

(b) Predictability Error of July forecast

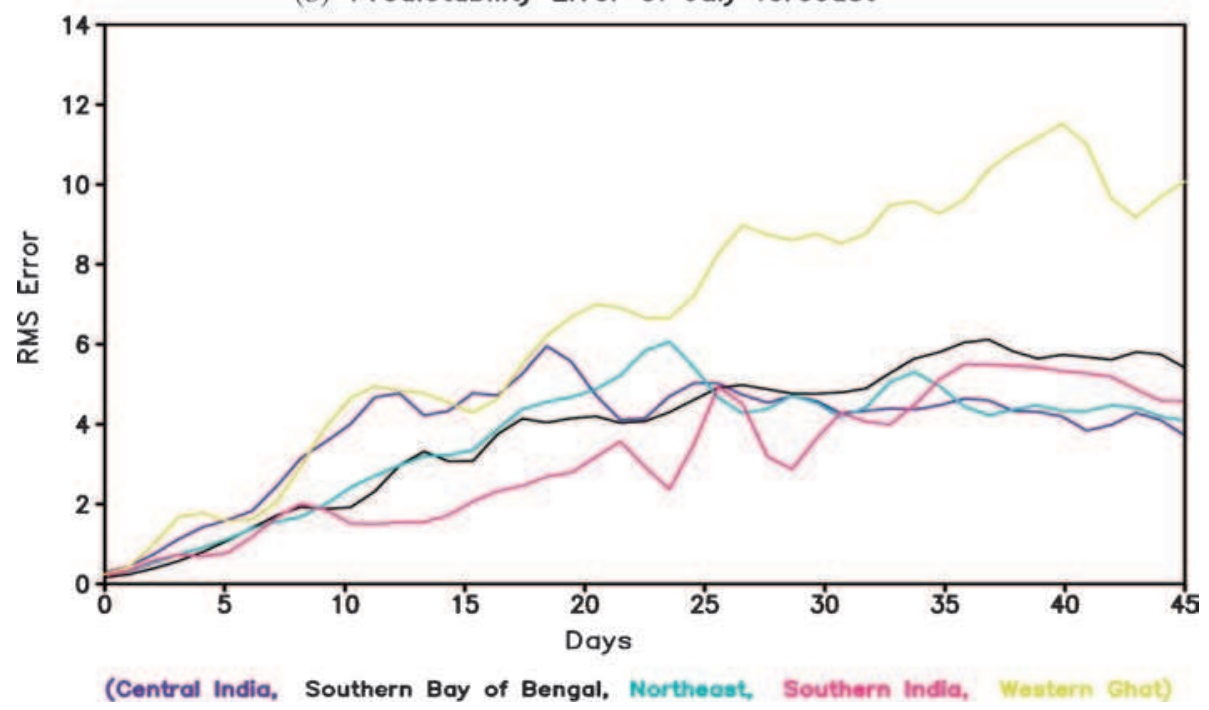

Figure 10. Similar to figure 9 , but the ocean part is also included in the five subdivisions. Units are in $\mathrm{mm}^{-1}$.

formula of equation 2 which shows a good approximation (figure 11). The nonlinear curve has been extrapolated backward (using equation 2) so that the initial error growth is in linear phase. In order to show this backward extrapolation to start at time zero, the predictability error has been shifted forward in time in figure 11. It is obvious that the magnitude of the initial error falls in the nonlinear phase of the error growth. However, Lorenz's nonlinear empirical formula is helpful in estimating the growth rate of small errors (Rai and Krishnamurthy 2011). The estimated value of $\lambda(=0.18)$ for land points of central India gives a doubling time of small error to be about 3.7 days. The doubling time predictability errors of the various regions, is computed and listed in table 1 for June and July forecasts. It is clear from table 1 that the June forecast in the case of IMR region is more predictable than July forecast, whereas for EIMR, July forecast is more predictable as compared to June forecast (rows 3 and 4 of table 1). However, the doubling time of each of the five subdivisions shows different doubling time for each forecast. The predictability of the southern Bay of Bengal and Western Ghats is slightly increased when the ocean parts are included, but it is decreased or unchanged for the rest of the subdivisions in case of June forecast (columns 2 and 3 of table 1 ). The predictability over the land points of southern India and Western Ghats is slightly improved for the July forecast as compared to June forecast, whereas opposite was true for IMR, central India, northeast, and southern Bay of Bengal region (columns 3 and 5 of table 1). It may be due to the fact that the June and July forecast gives the forecast from 1 June and 1 July, respectively. The onset of southwest 


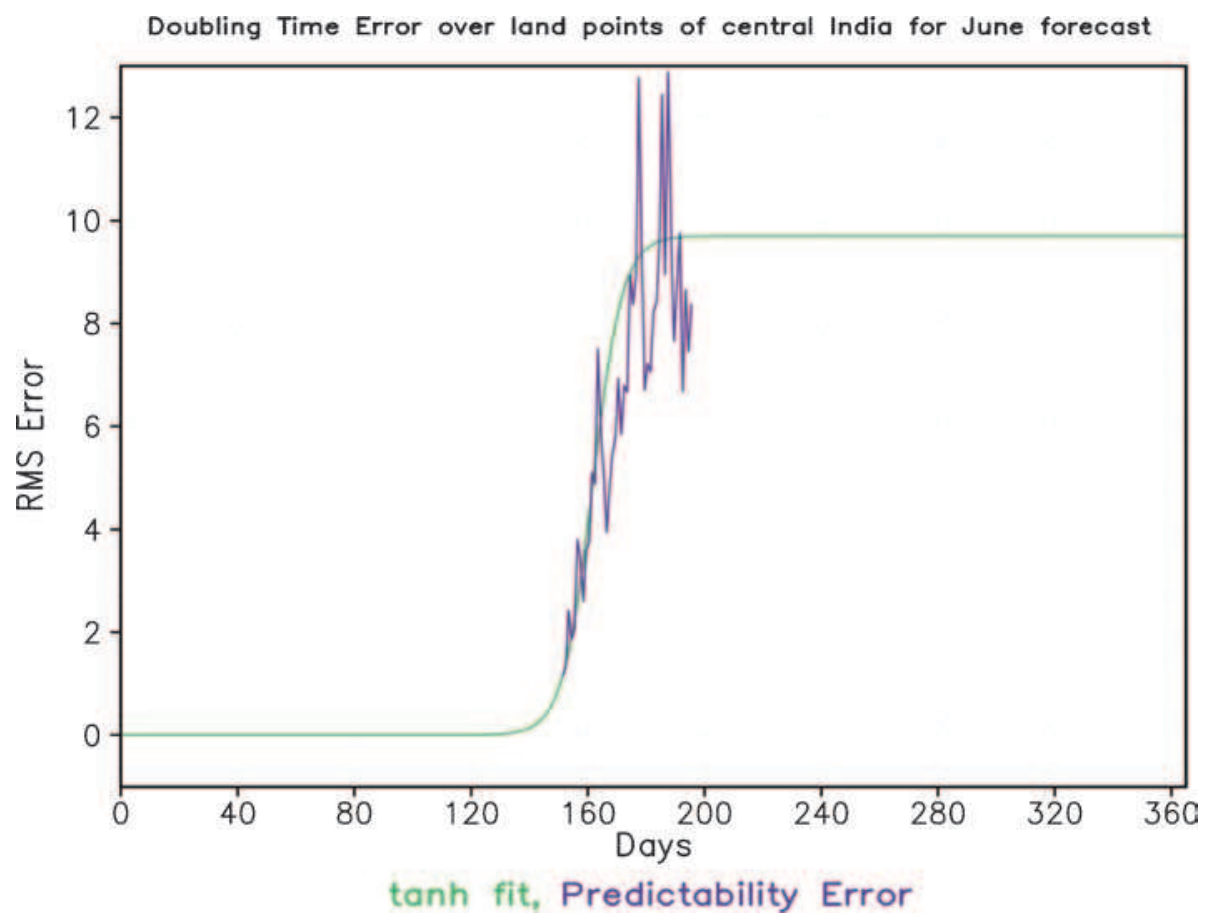

Figure 11. RMSE of predictability error (violet) for central India for June forecast. The green line is empirically fit curve according to Lorenz's formula. Units are in $\mathrm{mm} \mathrm{d}^{-1}$.

Table 1. The doubling time of errors of the NCEP CFSv2 forecast for different indices initialized on 31 May (June forecast) and 30 June (July forecast).

\begin{tabular}{|c|c|c|c|c|}
\hline \multirow[b]{2}{*}{ Regions } & \multicolumn{2}{|c|}{ June forecast } & \multicolumn{2}{|c|}{ July forecast } \\
\hline & Land and ocean & Land only & Land and ocean & Land only \\
\hline IMR & - & 3.9 & - & 3.5 \\
\hline EIMR & 3.7 & - & 3.9 & - \\
\hline Central India & - & 3.7 & - & 3.5 \\
\hline Southern Bay of Bengal & 4.1 & 3.7 & 5.0 & 3.4 \\
\hline Northeast & - & 3.6 & - & 3.5 \\
\hline Southern India & 3.4 & 3.6 & 3.9 & 3.7 \\
\hline Western Ghat & 3.0 & 2.9 & 4.0 & 3.8 \\
\hline
\end{tabular}

monsoon is supposed to be around 1 June from the southern tip of India and it is well set over the southern India and Western Ghats region up to 1 July. However, very less rainfall occurs in the month of June for IMR, northeast, central India and southern Bay of Bengal regions and monsoon picks up in the month of July for these regions. This may be the reason that the southern India and Western Ghats are more predictable in the July forecast as compared to June forecast, whereas IMR, northeast, central India and southern Bay of Bengal regions are having the opposite nature. The low predictability of central India, IMR and some parts of northeast region may also be due to the variation of monsoon trough in Indo-Gangetic plain in the month of July. The improvement in the predictability from July forecast is observed for southern Bay of Bengal region, northeast and southern India when the Ocean is also included (columns 2, 4 of table 1).

\section{Conclusion}

The main objective of this study is to estimate the forecast skill and predictability of the south Asian summer monsoon as well as over various subdivisions of the Indian subcontinent in CFSv2. The evolution of daily, seasonal cycle, monthly bias, forecast error and predictability error are evaluated during Indian summer monsoon season.

The seasonal cycles of the daily climatological mean precipitation over the land points is underestimated by the model and is in agreement with some of the recent studies (Sahai et al. 2013; Sharmila et al. 2013; Abhilash et al. 2014b; 
Goswami et al. 2014; Bombardi et al. 2015) and it is also found in the previous version of CFS (Rai and Krishnamurthy 2011; Abhilash et al. 2014a). The monthly bias shows that the model underestimates the rainfall over the land points of India and Bay of Bengal, whereas it overestimates over the Arabian Sea and the Himalayan region as compared to observation. This underestimation of precipitation over land points of India in CFSv1 (Rai and Krishnamurthy 2011; Pattanaik and Kumar 2014) still persists in the CFSv2. The EIMR index shows a better agreement with respect to observation as compared to IMR because the overestimation at oceanic region and underestimation over land are balanced. We have divided the Indian landmass into five subdivisions based on the spatial variation of mean observed precipitation in JJAS season. The seasonal cycle of these subdivisions show that the underestimation of precipitation during the mature phase of the monsoon in IMR region comes mostly from central India, southern Bay of Bengal, southern India and Western Ghat regions.

The growth of forecast and predictability errors for all the indices have been computed with respect to GPCP and IMD observations and it is found that the growth pattern is dependent on the initial conditions and spatial domain. The error growth of June forecast is slower as compared to July forecast in CFSv2 for all the regions as was observed from CFSv1 (Krishnamurthy and Shukla 2011; Rai and Krishnamurthy 2011). The predictability error also grows slowly in June forecast as compared to July forecast. In the present study, we have observed that the predictability of CFSv2 is up to 3 weeks, while in the CFSv1, it was about 1-2 weeks (Abhilash et al. 2013; Pattanaik and Kumar 2013). It was found that the southern India and Western Ghats are more predictable in the July forecast as compared to June forecast and opposite is true for IMR, northeast, central India and southern Bay of Bengal regions. The doubling time of the predictability error is in the range of $3-5$ days for all the regions.

It has been observed that the nature of error growth and saturation time depend on model initialization and it is different for various subdivisions of Indian subcontinent. The model predictability is completely lost when the error of model reaches to saturation value (DelSole 2004). The doubling time of error computed in the present work gives an idea of rate of growth for predictability and forecast error and it may be assumed that our forecast is good enough until these errors reach at its saturation value.

\section{Acknowledgements}

Authors would like to thank the Ministry of Earth Science (MoES) and Indian Institute of Tropical Meteorology (IITM), Pune for financial support under National Monsoon Mission Project, No. MM/SERP/Univ-Allahabad/2013/IND-6/002. SR would like to thank $\mathrm{V}$ Krishnamurthy of IGES/COLA, USA for scientific discussion related to error growth analysis.

\section{References}

Abhilash S, Sahai A K, Pattnaik S and De S 2013 Predictability during active break phases of Indian summer monsoon in an ensemble prediction system using climate forecast system; J. Atmos. Sol. Terr. Phys. 100-101 13-23, doi: 10.1016/j.jastp.2013.03.017.

Abhilash S, Sahai A K, Pattnaik S, Goswami B N and Kumar A 2014a Extended range prediction of activebreak spells of Indian summer monsoon rainfall using an ensemble prediction system in NCEP climate forecast system; Int. J. Climatol. 34 98-113, doi: 10.1002/joc.3668.

Abhilash S, Sahai A K, Borah N, Chattopadhyay R, Joseph S, Sharmila S, De S, Goswami B N and Kumar A 2014b Prediction and monitoring of monsoon intraseasonal oscillations over Indian monsoon region in an ensemble prediction system using CFSv2; Clim. Dyn. 42 2801-2815.

Bengtsson L and Hodges K I 2006 A note on atmospheric predictability; Tellus 58A 154-157.

Bombardi R J, Schneider E K, Marx L, Halder S, Singh B, Tawfik A B, Dirmeyer P A and Kinter III J L 2015 Improvements in the representation of the Indian summer monsoon in the NCEP climate forecast system version 2; Clim. Dyn. 45(9) 2485-2498.

Buizza R, Leutbecher M and Isaksen L 2008 Potential use of an ensemble of analyses in the ECMWF ensemble prediction system; Quart. J. Roy. Meteorol. Soc. 134 2051-2066.

DelSole T 2004 Predictability and information theory. Part I: Measures of predictability; J. Atmos. Sci. 61(20) 2425-2440.

DelSole T and Shukla J 2012 Climate models produce skillful predictions of Indian summer monsoon rainfall; Geophys. Res. Lett. 39 L09703, doi: 10.1029/2012GL051279.

Drbohlav H K L and Krishnamurthy V 2010 Spatial structure, forecast errors and predictability of south Asian monsoon in CFS monthly retrospective forecasts; J. Clim. 23 4750-4769.

Gadgil S and Sajani S 1998 Monsoon precipitation in the AMIP runs; Clim. Dyn. 14 659-689.

Gadgil S, Rajeevan M and Nanjundiah R 2005 Monsoon prediction - Why yet another failure?; Curr. Sci. 9 13891400.

George S E and Sutton R T 2006 Predictability and skill of boreal winter forecasts made with the ECMWF seasonal forecasting system II; Quart. J. Roy. Meteorol. Soc. 132 2031-2053.

Goswami B N, Krishnamurthy V and Annamalai H 1999 A broad-scale circulation index for the interannual variability of the Indian summer monsoon; Qurt. J. Roy. Meteorol. Soc. 125 611-633.

Goswami B B, Deshpande M, Mukhopadhyay P, Saha S K, Rao S A, Murthugudde R and Goswami B N 2014 Simulation of monsoon intraseasonal variability in NCEP CFSv2 and its role on systematic bias; Clim. Dyn. 43 2725-2745. 
Griffies S M, Harrison M J, Pacanowski R C and Rosati A 2004 A technical guide to MOM4, GFDL ocean group technical report no. 5, Princeton, NJ, NOAA/Geophysical Fluid Dynamics Laboratory.

Guhathakurta P, Rajeevan M, Sikka D R and Tyagi A 2014 Observed changes in southwest monsoon rainfall over India during 1901-2011; Int. J. Climatol., doi: 10.1002/joc.4095.

Huffman G J, Adler R F, Morrissey M M, Bolvin D T, Curtis S, Joyce R, McGavock B and Susskind J 2001 Global precipitation at one-degree daily resolution from multisatellite observations; J. Hydrometeor. 2 36-50.

Kang I S, Jin K, Wang B, Lau K M, Shukla J, Krishnamurthy V, Schubert S D, Wailser D E, Stern W F, Kitoh A, Meehl G A, Kanamitsu M, Galin V Y, Satyan V, Park C K and Liu Y 2002 Intercomparison of the climatological variations of Asian summer monsoon precipitation simulated by 10 GCMs; Clim. Dyn. 19 383-395.

Kang I S, Lee J Y and Park C K 2004 Potential predictability of summer mean precipitation in a dynamical seasonal prediction system with systematic error correction; J. Clim. 17 834-844.

Kang I S and Shukla J 2006 Dynamical seasonal prediction and predictability of monsoon; In: The Asian monsoon (ed.) Wang B, Springer/Praxis Publishing Co., New York.

Kashid S S and Maity R 2012 Prediction of monthly rainfall on homogeneous monsoon regions of India based on large scale circulation patterns using genetic programming; J. Hydrol. 454 26-41.

Krishnamurthy V 1993 A predictability study of Lorenz's 28-variable model as a dynamical system; J. Atmos. Sci. $502215-2229$.

Krishnamurthy V and Rai S 2011 Predictability of south Asian monsoon circulation in the NCEP climate forecast system; Adv. Geosci. 22 65-76.

Krishnamurthy V and Shukla J 2001 Observed and model simulated interannual variability of the Indian monsoon; Mausam 52 133-150.

Krishnamurthy V and Shukla J 2011 Predictability of the Indian monsoon in coupled general circulation models; COLA Technical Report 313.

Kumar K K, Hoerling M and Rajagopalan B 2005 Advancing dynamical prediction of Indian monsoon rainfall; Geophys. Res. Lett. 32 L08704, doi: 10.1029/2004GL021979.

Kumar V, Jain S K and Singh Y 2010 Analysis of long term rainfall trends in India; Hydrol. Sci. J. 55 484496.

Kug J S, Ham Y G, Kimoto M, Jin F F and Kang I S 2010 New approach for optimal perturbation method in ensemble climate prediction with empirical singular vector; Clim. Dyn. 35(2-3) 331-340.

Lorenz E N 1965 A study of the predictability of a 28variable atmospheric model; Tellus 17 321-333.

Lorenz E N 1969 Atmospheric predictability as revealed by naturally occurring analogues; J. Atmos. Sci. 26(4) 636-646.

Lorenz E N 1982 Atmospheric predictability experiments with a large numerical model; Tellus 34 505-513.

Lorenz E N 1985 The growth of errors in prediction; In: Turbulence and Predictability in Geophysical Fluid Dynamics and Climate Dynamics (eds) Ghil M and Benzi R, pp. 243-265.

Mohan R S A and Goswami B N 2003 Potential predictability of the Asian summer monsoon on monthly and seasonal time scales; Meteorol. Atmos. Phys. 84 83-100.
Pai D S, Sridhar L, Badwalk M R and Rajeevan M 2014 Analysis of the daily rainfall events over India using a new long period (1901-2010) high resolution $\left(0.25^{\circ} \times 0.25^{\circ}\right)$ gridded rainfall data set. Clim. Dyn., doi: $10.1007 / \mathrm{s} 00382-014-2307-1$.

Pattanaik D R and Kumar A 2013 Comparison of intraseasonal forecast of Indian summer monsoon between two versions of NCEP coupled models; Theor. Appl. Climatol. $118331-345$.

Pattanaik D R and Kumar A 2014 A hybrid model based on latest version of NCEP CFS coupled model for Indian monsoon rainfall forecast; Atmos. Sci. Lett., doi: $10.1002 /$ asl2.513.

Rai S and Krishnamurthy V 2011 Error growth in climate forecast system daily retrospective forecasts in south Asian monsoon; J. Geophys. Res. 116 D03108, doi: 10.1029/2010JD014840.

Rajeevan M, Guhathakurta P and Thapliyal V 2000 New models for long range forecasts of summer monsoon rainfall over northwest and peninsular India; Meteorol. Atmos. Phys. 73 211-225.

Rajeevan M 2001 Prediction of Indian summer monsoon: Status, problems and prospects; Curr. Sci. 11 1451-1458.

Rajeevan M, Pai D S, Dikshit S K and Kelkar R R 2004 IMD's new operational models for long-range forecast of southwest India, monsoon rainfall over their verification for 2003; Curr. Sci. 3 422-431.

Saha S, Moorthi S, Pan H L, Wu X, Wang J, Nadiga S, Tripp P, Kistler R, Woollen J, Behringer D, Liu H, Stokes D, Grumbine R, Gayno G, Wang J, Hou Y T, Chuang H Y, Juang H M H, Sela J, Iredell M, Treadon R, Kleist D, Delst P V, Keyser D, Derber J, Ek M, Meng J, Wei H, Yang R, Lord S, Dool H V D, Kumar A, Wang W, Long C, Chelliah M, Xue Y, Huang B, Schemm J K, Ebisuzaki W, Lin R, Xie P, Chen M, Zhou S, Higgins W, Zou C Z, Liu Q, Chen Y, Han Y, Cucurull L, Reynolds R W, Rutledge G and Goldberg M 2010 The NCEP climate forecast system reanalysis; Bull. Am. Meteor. Soc. 91 1015-1057.

Saha S K, Pokhrel S and Chaudhari H S 2013 Influence of Eurasian snow on Indian summer monsoon in NCEP CFSv2 freerun; Clim. Dyn. 41 1801-1815.

Saha S, Moorthi S, Wu X, Wang J, Nadiga S, Tripp P, Behringer D, Hou Y T, Chuang H Y, Iredell M, Ek M, Meng J, Yang R, Mendez M P, Dool H V D, Zhang Q, Wang W, Chen M and Becker E 2014a The NCEP climate forecast system, ver. 2; J. Clim. 27 2185-2208.

Saha S K, Pokhrel S, Chaudhri H S, Dhakate A, Shewale S, Sabeerali C T, Salunke K, Hazra A, Mahapatra S and Rao A S 2014b Improved simulation of Indian summer monsoon in latest NCEP climate forecast system free run; Int. J. Climatol. 34 1628-1641.

Sahai A K, Sharmila S, Abhilash S, Chattopadhyay R, Borah N, Krishna R P M, Joseph S, Roxy M, De S, Pattnaik S and Pillai P A 2013 Simulation and extended range prediction of monsoon intraseasonal oscillations in NCEP CFS/GFS version 2 framework; Curr. Sci. 104 1394-1408.

Savijarvi H 1994 Error growth in a large numerical forecast system; Mon. Wea. Rev. 123 212-221.

Sharmila S, Pillai P A, Joseph S, Roxy M, Krishna R P M, Chattopadhyay R, Abhilash S, Sahai A K and Goswami B N 2013 Role of ocean-atmosphere interaction on northward propagation of Indian summer monsoon intra-seasonal oscillations (MISO); Clim. Dyn. 41 16511669.

Shukla J 1981 Dynamical predictability of monthly means; J. Atmos. Sci. 38 2547-2572.

Shukla J 1985 Predictability; Adv. Geophys. 28B 87-122. 
Shukla J and Kirtman B 1996 Predictability and error growth in a coupled ocean-atmosphere model; COLA Tech. Rep. 24, 11p. [Available from COLA, 4041 Powder Mill Rd., Suite 302, Calverton, MD 20705.]

Simmons A J and Hollingsworth A 2002 Some aspects of the improvement in skill of numerical weather prediction; Quart. J. Roy. Meteorol. Soc. 128 647-677.

Smagorinsky J 1969 Problem and promises of deterministic extended range forecast; Bull. Am. Meteor. Soc. 50 286-311.
Straus D M and Paolino D 2009 Intermediate time error growth and predictability: Tropics versus mid-latitudes; Tellus A. 61 579-586.

Wang B, Kang I S and Lee J Y 2004 Ensemble simulations of Asian-Australian monsoon variability by 11 AGCMs; J. Clim. 17 803-818.

Wang B, Ding Q, Fu X, Kang I S, Jin K, Shukla J and Doblas R F 2005 Fundamental challenge in simulation and prediction of summer monsoon rainfall; Geophys. Res. Lett. 32, doi: 10.1029/2005GL022734. 